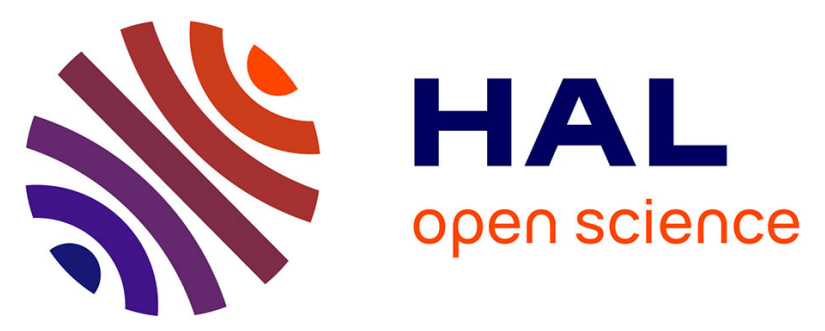

\title{
Fat and muscle mass in different groups of pre-pubertal and pubertal rural children. Cross-cultural comparisons between Sahelian (rural Senegal) and Amazonian (Beni River, Bolivia) children.
}

Eric Bénéfice, Selma J Luna Monrroy, Ronald W Lopez Rodriguez, Gnagna Ndiaye

\section{To cite this version:}

Eric Bénéfice, Selma J Luna Monrroy, Ronald W Lopez Rodriguez, Gnagna Ndiaye. Fat and muscle mass in different groups of pre-pubertal and pubertal rural children. Cross-cultural comparisons between Sahelian (rural Senegal) and Amazonian (Beni River, Bolivia) children.. Annals of Human Biology, 2011, 38 (4), pp.500-7. 10.3109/03014460.2011.564207 . ird-00613584

\author{
HAL Id: ird-00613584 \\ https://hal.ird.fr/ird-00613584
}

Submitted on 5 Aug 2011

HAL is a multi-disciplinary open access archive for the deposit and dissemination of scientific research documents, whether they are published or not. The documents may come from teaching and research institutions in France or abroad, or from public or private research centers.
L'archive ouverte pluridisciplinaire HAL, est destinée au dépôt et à la diffusion de documents scientifiques de niveau recherche, publiés ou non, émanant des établissements d'enseignement et de recherche français ou étrangers, des laboratoires publics ou privés. 


\section{Fat and muscle mass in different groups of prepubertal and pubertal rural children. Cross-cultural comparisons between Sahelian (rural Senegal) and Amazonian (Beni River, Bolivia) children}

\section{Running title: Fat and muscle mass in Sahelian and Amazonian children}

\section{Corresponding author:}

Eric Benefice (MD, $\mathrm{PhD})$

Affiliation: Senior scientist, IRD (Institut de Recherche pour le développement, France) Address: IRD, Ban Sisangvone, Saysettha district PO box: 5992, Vientiane (PDR Lao) Phone: (856 21) 452707

Fax: (856 21) 412993

Mobile: (856 20) 7526834

Email: eric.benefice@ird.fr

\section{Contributing authors}

Selma J Luna Monrroy selmalunamonrroy@,hotmail.com

Affiliation: Research assistant, Instituto SELADIS (Facultad de Ciencias Bioquímicas y Farmacéuticas, Universidad Mayor de San Andrés, La Paz, Bolivia)

Ronald W Lopez Rodriguez zelopr@hotmail.com

Affiliation: Junior scientist, INLASA, (Instituto Nacional de Laboratorios en Salud, Ministerio de Salud y Deportes), La Paz (Bolivia

Gnagna Ndiaye Gnagna.Ndiaye@wfp.org

Affiliation: Specialist Nutritionist /VAM UN World Food Programme, WFP CO Sénégal

Keywords: Anthropometry; nutritional stress; puberty; ethnic groups 
Fat and muscle mass in different groups of prepubertal and pubertal rural children. Cross-cultural comparisons between Sahelian (rural Senegal) and Lowland Bolivia (Beni River, Bolivia) children

Running title: Fat and muscle mass in Sahelian and Amazonian children

Keywords: Anthropometry; nutritional stress; puberty; ethnic groups 


\begin{abstract}
Background: An increase in fat accretion is essential for triggering the puberty spurt. Hence, nutritional constraints may influence puberty timing.

Objectives: To measure changes in fat and muscle mass in children living in natural environments but with different nutritional exposures.

Design: Cross-comparisons of children from rural Senegal and lowland (Amazonian) Bolivia.

Methods: Anthropometric measurements of stature, weight, four subcutaneous skinfolds (triceps, biceps, subscapular, supra-iliac) and arm circumference. Children were divided into two age groups (5-9.9-year-olds, or "pre pubescents" $(\mathrm{n}=381)$, and 10-15-year-olds, or "pubescents" $(\mathrm{n}=692))$.

Results: Senegalese girls menstruated later than Bolivian girls and Senegalese boys also matured later than Bolivian boys. Bolivian children displayed more fat and muscle before puberty and during puberty than the Senegalese. They also had more fat deposited on the trunk. There were substantial differences in living conditions and nutritional patterns between both locations. In Senegal, nutritional stress is likely to appear early during in utero life and to persist throughout the growth period, including puberty. This leads to a deficit in fat accretion before and during puberty that is associated with a considerable delay in puberty occurrence. In Bolivia, such stress is far less severe. Conclusion: Variability in puberty should be analyzed taking into account these differences.
\end{abstract}




\section{Introduction}

A classical observation has been that a sharp increase in fat mass occurs in girls during puberty, while boys accumulate relatively more muscle and fat free mass (Siervogel et al. 2003). However, there exists evidence that these differences existed prior to puberty (He et al. 2002). Sexual dimorphism not only affects fat mass but also fat distribution, with more peripheral (gynoid pattern) subcutaneous fat in girls and more trunk fat in boys (android pattern) (Malina et al. 1999). Sex differences in fat patterns are clearly under the influence of hormones like gonadal steroids and leptin (Horlick et al. 2000). Maturation of the adrenal axis during childhood appears to play an important role in the development of puberty, perhaps by connecting the increase in body weight and fat mass to sexual maturation. In the same way, longitudinal studies have demonstrated the existence of a link between the phenomenon of adiposity rebound (accumulation of fat at around 6 years of age) and earlier maturity and menarche (Williams and Dickson 2002). In addition, epidemiological studies point out that overweight girls are more advanced in puberty than normal girls of the same age (Adair and Gordon-Larsen 2001,Parent et al. 2003). Interestingly, comparative studies between different population groups show that ethnic differences in adiposity exist during prepubescence and are later associated with differences in puberty timing (Adair and Gordon-Larsen 2001, Greaves et al. 1989). Thus, there exists a cluster of presumptions that show direct relationships between prepubertal fat mass accretion and puberty timing.

The causal or consequential nature of fat accretion upon maturation is still subject to debate (Parent et al. 2003). However, it should be noted that most studies were performed in affluent countries where dietary intake did not constitute a limiting factor in growth and maturation. In developing countries, especially in population groups struggling for daily survival in hostile environments, malnutrition and food restrictions are known to cause delays in the onset of sexual maturation (Kulin et al. 1982). Indeed, very slow maturation has been reported in girls from Senegal, a Sahelian country of West Africa, where adolescent girls had a median age of 16.1 years at menarche (Simondon et al. 1997). This delay was later confirmed by a longitudinal study (Garnier et al. 2005). Boys 
also presented very slow growth during pubescence (Benefice 2007). A similar late onset of puberty was observed in other African groups, including the Turkana and Karamajong of Eastern Africa (Campbell et al. 2005, Gray et al. 2004).

Residence in a dry or humid tropical setting may provide a "natural experimental setting" for studying the impact of environmental factors on the variability of growth and maturation, in that "naturally occurring circumstances" will expose populations to different levels of a "supposed causal factor". In anthropological, epidemiological and ecological studies, true experimental research designs are difficult to elaborate, but "specialcireumstances or particular attributes of a given population may have direct relevance to the issue addressed" (Garruto et al. 1999). Comparison of extreme environments, stresses contrasts between ecological and cultural factors that may influence biological diversity. In the present study, the hypothesis was that the delay in puberty is associated with insufficiency of fat accretion during prepubescence, provoked by nutritional stress. Confrontation of groups having either a fast or slow puberty tempo, but which share a "traditional" way of life (characterized by food insecurity and nutritional breaks, heavy workloads (absence of mechanical facilities), high exposure to transmissible diseases and irregular access to modern medicine and health care) could provide more insight into the effect of environmental factors upon puberty and growth. 


\section{$\underline{\text { Studies context }}$}

\section{Senegalese studies}

The children and adolescents presented here were drawn from several surveys performed between 1995 and 2002 within the framework of a longitudinal study on growth, maturation and physical activity of West African children (Garnier and Benefice 2001). Children were from 3 areas of Senegal located at the Sahelian belt: Niakhar and Lambaye (central Senegal) and the Podor department, (Senegal River Valley, close to the border of Mauritania in the north).

The Senegalese climate is hot and dry, with sparse rains from July to October. Rainfalls vary between 300 and $600 \mathrm{~mm}$. Inhabitants are Muslims farmers and herders belonging to related ethnic groups: Tokolor in the north (Podor) and Wolof (Lambaye) and Serer (Niakhar) in the center. All groups share a common Sahelian culture with similar agricultural practices. They grow millet (Pennisetum spp. and Sorghum vulgare) in association with beans (Vigna unguiculata). In Lambaye and Niakhar, they grow peanuts (Arachis hypoogea) for cash. In the Senegal River Valley, modern irrigation permits rice cultivation. The basic diet consists of a bowl of rice with fresh or dried fish at noon and millet couscous with peanut sauce in the evening. Malnutrition is ubiquitous in Senegal: according to the last Demographic and Health Survey database (2005). These data are freely available on line (http://www.measuredhs.com/), more than $21 \%$ of preschool children are stunted (height-for-age $<-2$ z-scores) and 9\% are wasted (weight-for-height $<-2$ z-scores).

\section{The Lowland Bolivia study (Beni department)}

From 2004 to 2005, a study on the health and nutritional status of communities living on the banks of the Beni River (Lowland Bolivia) was performed (Benefice et al. 2006). It was a cross-sectional survey. The study was carried out below the $200 \mathrm{~m}$ contour in an area characterized by a humid hot climate (mean temperature of $22-24^{\circ} \mathrm{C}$ ) and by high annual rainfall $(>2500 \mathrm{~mm})$. Inhabitants belonged to two related Amerindian ethnic groups: most of them were Takanas (148 families out of 171) and the others were Esse 
Ejjas. They grow tubers (cassava root), plantains, rice and maize for subsistence. They worked as woodcutters for cash. They obtained a substantial part of their animal food through hunting and fishing. Fishing was an important activity. Sometimes they sold their surplus fish in the cities for income.

According to a recent Demographic and Health Survey (2004), the nutritional status of children in this province was mediocre, with $37 \%$ of stunting but only $1.5 \%$ of wasting, in preschool children.

\section{$\underline{\text { Subjects and methods }}$}

Two age groups, 5-9.9-year-olds, or "pre pubescents", and 10-15-year-olds, or "pubescents", were used so as to avoid interactions between age and geographic location. In Senegal a total of 196 pre pubescent and 595 pubescent children were seen (see table 1 for sex and age categorization) were seen. In Lowland Bolivia, the number was less: 185 prepubescent and 97 pubescent children.

\section{Anthropometric measurements (linear growth and body composition)}

The same methods were used in both studies. Anthropometric measurements followed the recommended procedures (Lohman et al. 1988). Children were weighed (kg) barefoot and in underpants with an electronic scale accurate to $100 \mathrm{~g}$. Then the stature $(\mathrm{cm})$ was measured standing upright, with eyes on a horizontal plane, with a Harpenden $\mathbb{}$ anthropometer. Arm circumference $(\mathrm{cm})$ was measured at mid-distance between the acromion and oleocranion with an unstretchable tape. Four subcutaneous skinfolds (tricipital, bicipital, subscapular and supra-iliac, $\mathrm{mm}$ ) were recorded with a Holtain ${ }^{\circledR}$ caliper after marking the site on the skin. These measurements were taken on the left side. All measurements were done in duplicate and the average value was used in the calculation to minimize the variance.

The sum of 4 skinfolds ( $\Sigma 4$ skf, mm) was used as an index of total subcutaneous fat mass. Relative fat regional distribution was assessed by the trunk-to-extremities ratio 
$(\mathrm{TER}=($ subscapular + supraliliac $)$ skinfolds $/($ triceps + biceps $)$ skinfolds $)$. Finally, arm muscle circumference (AMC, cm), considered to be an index of muscularity, was calculated as: $\mathrm{AMC}=\mathrm{AC}-\pi *$ (triceps skinfold) (Gurney and Jelliffe 1973). The body mass index (BMI, $\mathrm{kg} / \mathrm{m}^{2}$ ) was calculated as (weight $/$ stature $^{2}$ ) and served as an indicator of general corpulence.

In Senegal, at the beginning of each survey, measurements were also done in duplicate by the observer to calculate an intra-observer coefficient of variation. Interobserver coefficients of variation were low for stature $(0.2 \%)$, arm circumference $(2.4 \%)$ and for diameters $(2.7 \pm 3 \%)$. They were higher for skinfolds $(5.2 \%$ for tricipital and $10.8 \%$ for supra-iliac). (Benefice et al. 2001b). In Bolivia, only one observer (EB) did all measurements.

An index of growth retardation based on deviance of observed stature from the WHO (World Health Organization) / CDC (Center for Disease Control of Atlanta, USA) reference norms was computed. It is termed "height for age" (H-age) and is expressed in Z-scores.

\section{Maturation}

In the present study, pubertal maturity was estimated according to a single robust indicator in girls: the occurrence of menstruation. Longitudinal observations of adolescent Senegalese girls permits precise estimation using a log normal parametric survival model (Garnier et al. 2005). In Bolivia, a status quo method was used in all girls older then 10 and a probit analysis done.

The onset of a voice change and axillary hairiness in boys served as indices of puberty. In addition, peak height velocity was calculated in Senegalese boys with the Preece and Baines model (Preece and Baines 1978). It was not possible to fit a curve in Amerindian children from Lowland Bolivia because of the small sample. 


\section{Ethical considerations}

Senegalese studies were approved by a joint annual review board of the French Institute for Development (Institut de Recherche pour le Développement, IRD) and the Senegalese Ministry of Research. Surveys protocol were submitted to and approved by the Comite National d'Ethique du Sénégal, installed by the Direction des Etudes, de la Recherche et de la Formation of the Senegalese Ministry of Health. Parents and political and religious leaders were informed of the aim of the studies. Oral consent was requested from parents and adolescents because most of them were illiterate.

In Bolivia, the objective of the study was explained to the head of family and to health officials and community and administrative authorities. The project was approved by the SELADIS (Biomedical Institute of the La Paz University, Biochemical \& Pharmacy Department) review board. The National Bioethics Committee of Bolivia and the Consultative Committee for Deontology and Ethics (IRD, France) gave their agreement. Children and parents were individually notified as to the aim of study and signed an informed consent form.

\section{Statistical analysis}

Variables were checked for normality. For the BMI, $\sum 4$ skf and TER, values were slightly skewed to the left, but after log transformation they normalized in each age and sex group. Comparisons between populations and age and sex groups were done with a general linear model approach using analysis of variance and covariance. Differences in linear growth (represented by height or H-age), total subcutaneous body fat ( $\left.\sum 4 \mathrm{skf}\right)$, corpulence (BMI) and regional body fat distribution (TER) were first studied between sex and age groups and within each geographic location. Then, comparisons were carried out between geographic locations in each sex and age group separately. The existence of a significant linear trend with age or location was investigated and analyzed. A p value of $5 \%$ was accepted as a threshold for statistical significance. 


\section{Results}

Demographic and nutritional characteristies of the two geographical locations appear in Table I. Data were drawn from the Demographic \& Health Survey database. These data are freely available on line (http://www.measuredhs.com/). Surveys were carried out in2004 and published in 2005 in Senegal (Enquête Démographique et de Santé: Sénégat 2005, Avril 2006) and performed in 2003 and published in 2004 in Bolivia (Eneuesta Naeional de Demografía y Salud: ENDSA 2003, Noviembre 2004). We used values from fural areas and, in some cases, from the provinces where datare collected. In the caseof Bolivia, numbers strveyed by DHS in the Amazonian departments of Lowland Bolivia and Pando were small and did not necessarily truly represent Amerindian communities living along the Lowland Bolivia River. Results for the whole country would appear to be more accurate.

According to Demographic \& Health Survey database, differences between countries were clear-cut. Senegal presented less favorable indicators of mortality and nutrition than Bolivia. Senegalese women had higher indices of fertility. The prevalence of growth retardation (representing chronic malnutrition) among 0 -5-year-old children was higher in Bolivia than in Senegal. The prevalence of wasting (representing acute malnutrition) recorded in Lowland Bolivia was the highest in Bolivia (3.3\%). However, there was virtually no severe malnutrition in the present sample. Instead, the prevalence of wasting was very high in Senegal (7\%). Women shorter than $145 \mathrm{~cm}$, an indicator of dystocies risk, were more numerous in Bolivia than in Senegal.

\section{Evidence of differences in puberty tempo between Bolivia and Senegal}

Longitudinal observations of adolescent Senegalese girls from a log normal parametric survival model offered a median age at menarche of 15.9 years (95\% CI 1/4 15.7-15.9 yr).. In Bolivia, a status quo method was used in all girls older then 10. The probit analysis gave a median age at first menstruation of 12.9 years, with a standard error of 0.34 years. 
In boys, estimates were less precise. In Senegal, signs of sexual maturity (change in voice pitch, attainment of adult voice and axillary hair) seemed to appear later, after 16 years of age. Calculation of age at peak height velocity (PHV) as an index of mid-puberty confirmed this observation. Age at PHV was equal to 16.4 years (estimated error of the function: 0.38) (Benefice 2007). The sample of Bolivian boys was too small to permit an accurate evaluation. However, clinical observation of axillary hair and voice change indicated that by 13 years of age, children were entering puberty. These observations strongly suggested that children from Senegal had delayed puberty compared with Bolivian children. In the present paper, we thus consider Senegalese children to be late maturers and Bolivian children to be normal or early maturers.

\section{Differences within a geographic location}

Table I displays anthropometric measurements stratified by sex, age group and geographic location. The number of adolescents seen in Bolivia and Senegal differed; however, categorization by sex and age remained balanced.

In Senegal (Table II a and b), a significant age effect was noteworthy in the prepubescent group for all indices apart the BMI ( $\mathrm{p}=0.06$ for H-age index). However, there were no sex differences except for $\sum 4$ skf: girls had higher values than boys (Table II a). In pubescent children, sex differences were more pronounced: girls were taller and more corpulent than boys (Table II b). Figures were different in Lowland Bolivia, where sexual dimorphism in muscle and fat mass was clearly apparent in prepubescent children: girls were less muscular, but fatter than boys (Table III a). Among pubescent children, girls had higher BMI and were fatter than boys, but differences in $\mathrm{H}$-age and muscle mass no longer existed (Table III b). Relative fat mass distribution, represented by TER, presented a significant increase with age whatever the location (more fat deposit on the trunk), but sex differences were apparent only in pubescent adolescents from Lowland Bolivia. 


\section{Differences between geographic locations}

Previous results pointed to a difference in the sequence of events between populationgroups. To further explore this point, comparisons were repeated between geographic locations for each sex and age group separately. In boys (Table IV), prepubescent as well as pubescent children from the Lowland Bolivia were significantly more muscular and more corpulent than their Senegalese peers. Prepubescent Bolivian children were smaller than the Senegalese children; however, no difference in stature was observed in pubescent boys. The same differences according to geographic location were noted in girls (Table V). Girls from Lowland Bolivia had higher indices of muscle and fat mass than girls from Senegal. Conversely, they were smaller both during the prepubescent and pubescent period. There also existed differences in fat mass distribution for each age and sex group: children from Lowland Bolivia consistently had more trunk fat (higher TER) than Senegalese children. 


\section{Discussion}

This study demonstrates that differences in fat and muscle mass between children from rural Senegal and those from lowland (Amazonian) Bolivia become evident starting at prepubescence. Sexual dimorphism in body composition indices was discernible during

prepubescence in Lowland Bolivia, whereas this was less clear-cut in Senegal. Prepubescent and pubescent children from Lowland Bolivia tended to accumulate more fat on the trunk than children from Senegal. The latter is important, since subcutaneous fat tracking exists between childhood and adulthood (Malina et al. 1995). Higher fat accumulation on the trunk in early adolescence is a recognized risk factor for centralized obesity and metabolic diseases later during adulthood (Rolland-Cachera et al. 1990). Indeed, though it was not the topic of this paper, the prevalence of overweight in women from Lowland Bolivia was found to be $35 \%$. These differences in physique were associated with a considerable delay in pubertal onset in Senegal, but not in Bolivia. However, earlier menarche in girls from Lowland Bolivia compared with Senegal did not seem to influence the median age at first pregnancy. It was only slightly higher in Senegal than in Bolivia (20 years versus 19 years). This suggests that the infertility period after the first menstruation may be longer in Lowland Bolivia.

While the cross-sectional nature of the Bolivian sample does not enable us to make sound conclusions, some speculation can be advanced. It is generally admitted that the puberty tempo differs markedly between groups of populations of different ethnic and genetic origin. In addition, ethnicity is a determining factor in physique characteristics and fat patterns (Adair and Gordon-Larsen 2001,Malina et al. 1995). However, most of those studies were performed in industrialized and developed countries, where the impact, upon growth and maturation, of environmental factors such as the infectious disease burden and food shortage is likely to be minor. This implies that heredity was of foremost importance in all of these studies. Twin studies indicate that heritable factors explain 70$80 \%$ of variability in puberty timing (Parent et al. 2003). In the present paper, 
comparisons were made between two different tropical populations for which, in addition to a genetic influence, environmental factors might play an important role.

In the first instance, we will examine the issue of physical characteristics observed here. Indeed, the dissimilarity between children from geographic locations raises the question of whether the studied children were truly representative of children generally living in their respective milieus.

\section{Slow growth and maturation rates in Senegal resulting in a "tall thin" appearance}

A physique characterized by leanness and thinness had already been described three decades ago within the same Sereer ethnic group (Benyoussef et al. 1973). Likewise, analysis of age at first menstruation using a national representative sample of girls confirmed that Senegalese girls menstruated later than in industrialized countries (upper limit: 12.8 years of age) (Adair and Gordon-Larsen 2001). This figure should be compared to 15.9 years (CI 95\%, 15.7 16.0) currently. In addition, the onset of puberty, as assessed by breast development (B2 stage according to Tanner's classification) was 12.6 years ( $\mathrm{CI}_{95 \%}: 12.5 \sim 12.8$ ) (Garnier et al. 2005). In the USA, it occurs 1.5 to 2 years earlier (Sun et al. 2002). We did not obtain an accurate measurement of sexual maturation among boys, but a discernible peak of height velocity was observed at 16.4 years (Benefice 2007). Such a peak is usually observed at about 13 years of age in industrialized nations. Interestingly, both Senegalese boys and girls were of normal size for their age during childhood, but were shorter than the international norm thereafter during pubescence. This is undoubtedly a reflection of their slow and prolonged growth. Indeed, a recent study indicated that young adults (20-25 years) belonging to the same Sereer ethnic group had an average stature of $161.3 \mathrm{~cm}$ for females and $174.0 \mathrm{~cm}$ for males. Thus, the final stature fit well with the median of international references.

A similar delay in sexual maturation has been reported in children belonging to pastoral groups in Turkana and Karamajong in East Africa. These groups were tall and slim, with 
a slow growth rate during puberty. A recent paper confirms that adolescent Turkana boys presented a considerable delay in puberty. Enlargement of testicular volume was first noted at $16.0 \pm 1.9$ years (Campbell et al. 2005). This would correspond to the G2 stage of Tanner (Tanner 1962). A G2 stage of around 9.2 to 10.03 was observed in the NHANES III study (Sun et al. 2002). This delay in puberty onset is concomitant with a very low level of blood testosterone (Campbell et al. 2005). In girls, age at first menstruation was estimated by Sandra Gray to be 16.5 years. Moreover, it should be emphasized that Senegalese as well as Turkana and Karamajong children lived in a similar dry area bordered by semi desert lands to the north and tropical savannahs to the south.

\section{Average pubertal timing in Lowland Bolivia and a "short and plump" appearance}

Data from the Amazon are far scarcer than for Africa. In the Lowland Bolivia province of Bolivia, children appeared to be small and somewhat plump. In comparison with Senegalese children, girls and boys were significantly more corpulent before and during puberty ( 1.9 to $2.5 \mathrm{~kg} / \mathrm{m}^{2}$ difference in boys and 1.6 to $1.7 \mathrm{~kg} / \mathrm{m}^{2}$ difference in girls). However, they presented an important deficit in H-age (greater than $-1.5 \mathrm{z}$-scores). This phenotype, sometimes referred to as "short and plump"(Martorell et al. 1987), has been described in other Amazonian tribes (Santos and Coimbra Junior 1991). Pubertal timing of children from Lowland Bolivia apparently fell within the range of industrialized countries. Only a few studies on puberty exist among adolescents living in the Amazon. A recent paper reported a median age of $12.3 \pm 1.7$ years at menarche in a "Caboclo" community (the Caboclo are a group of peasant colonists of mixed origin). In the Tsimane, an ethnic group from Lowland Bolivia living near our study site, first menstruation occurred at 13.9 years of age. This represents a one year delay compared to our sample (12.9 years). Tsimane girls also presented a peak height velocity at 13.0 years and boys at 14.0 years (cited in (Walker et al. 2006). 


\section{Impact of environmental factors}

Physical characteristics of the two groups were thus in satisfactory agreement with reports from similar ecological areas. It could be argued that linear growth mainly depends on genetic factors, whereas fat mass accretion depends on environmental conditions. In the present paper, fat accumulation was associated with earlier sexual maturation. Whether such an association was causal or simply correlational remains a matter of debate. The fact that children from Lowland Bolivia accumulate a significantly higher amount of fat than Senegalese children during prepubescence is likely to be associated with their living and growth conditions. We will thus examine three main factors known to influence sexual maturity, which differs between Bolivia and Senegal.

The first factor is that of in utero growth conditions that might influence subsequent development during childhood and adolescence (Claris et al.). We did not have accurate information concerning the birth weight of children studied here. Among the urban poor in Senegal, about $25 \%$ of newborns weighed less than 2,500 g. In lowland Bolivia, the birth weight range falls within acceptable limits according to local hospital records. An indirect index of fetal growth failure is the neonatal mortality rate (mortality during the $1^{\text {st }}$ month of life). According to the DHS surveys, it was about 3.5 times higher in rural Senegal than in lowland Bolivia. In utero growth retardation may postpone the pubertal maturation of Senegalese children compared to children from Lowland Bolivia.

The second factor is that of energy expenditure. It is recognized that energy imbalance created by a high level of physical activity can generate hypothalamic dysfunction (GnRH suppression) and hypoestrogenism (Warren and Perlroth 2001). This anomaly is usually transient, but a delay in puberty timing is observed in young gymnasts and dancers. The Senegalese girls and boys studied by our group had a very high level of activity (Ndiaye and Benefice 2007). These observations fit with postponement of maturity. We do not have such information for Lowland Bolivia. Observations suggest that subsistence activity loads are higher in Senegal (for example, tasks like fetching water, carrying wood and grinding grain are less frequent in the Lowland Bolivia 
province). Similar conclusions were drawn in a study on Nicaraguan girls compared with adolescents from Mali (Pawloski et al. 2004).

The third factor is dietary intake, both quantitative and qualitative. Low energy intake could be associated with later age at menarche (Riley 1994) and conversely, a predominance of protein of animal origin in the diet was also linked to earlier age at menarche. In the Senegalese sample, we found acceptable average energy intakes; however, the range of variation was high: $40 \%$ of adolescents actually did not meet their nutritional requirements. The intake of food of animal origin was very low (Benefice et al. 2001a). In Lowland Bolivia, most of the energy need was covered by bulky foods like cassava and plantain banana. However, items of animal origin (including fish and game meat) provided about $25 \%$ of energy needs and were the first source of protein (unpublished data). Senegalese children might also be more nutritionally stressed because of the recurrence of seasonal food shortage.

\section{Conclusions}

It is reasonable to state that Senegalese children experience more marked nutritional stress than Bolivian children. This stress extends its effects throughout growth, from the prenatal period up until adolescence. It ultimately results in delayed puberty. This is reflected in differences in anthropometric indices of fat and muscle mass and relative fat distribution between the two countries. This end result points to the importance of fat mass accretion during childhood for triggering the onset of puberty (Adair and GordonLarsen 2001,Parent et al. 2003). 


\section{References}

Adair, L. S.and Gordon-Larsen, P., 2001, Maturational timing and overweight prevalence in US adolescent girls. Am J Public Health, 91, 642-644.

Benefice, E., 2007, Growth spurt, relative fat distribution and physical activity of Senegalese rural male adolescents. Journal of Exercise Science and Physiotherapy, 3, $55-64$.

Benefice, E., Garnier, D.and Ndiaye, G., 2001a, High levels of habitual physical activity in west African adolescent girls and relationship to maturation, growth, and nutritional status: results from a 3-year prospective study. Am J Hum Biol, 13, 808820.

Benefice, E., Garnier, D., Simondon, K. B.and Malina, R. M., 2001b, Relationship between stunting in infancy and growth and fat distribution during adolescence in Senegalese girls. Eur J Clin Nutr, 55, 50-58.

Benefice, E., Monrroy, S. L., Jimenez, S.and Lopez, R., 2006, Nutritional status of Amerindian children from the Beni River (lowland Bolivia) as related to environmental, maternal and dietary factors. Public Health Nutr, 9, 327-335.

Benyoussef, A., Cutler, J. L., Baylet, R., Collomb, H., Diop, S., Lacombe, B., Vaugelade, J.and Levine, A., 1973, [Health, migration and urbanization: a collaborative study in Senegal]. Bull World Health Organ, 49, 517-537.

Campbell, B. C., Leslie, P. W., Little, M. A.and Campbell, K. L., 2005, Pubertal timing, hormones, and body composition among adolescent Turkana males. Am J Phys Anthropol, 128, 896-905.

Claris, O., Beltrand, J.and Levy-Marchal, C., 2010, Consequences of intrauterine growth and early neonatal catch-up growth. Semin Perinatol, 34, 207-210.

Diop, N. J., 1994, La dynamique de la fécondité des adolescentes au Sénégal. African Population Studies / Etude de la Population Africaine, 9, Code Number: ep94005.

Ferry, B., 1976, Données récentes sur la fécondité à Dakar (Sénégal). Population (French Edition), 31e Année, 717-722.

Garnier, D.and Benefice, E., 2001, Habitual physical activity of Senegalese adolescent girls under different working conditions, as assessed by a questionnaire and movement registration. Ann Hum Biol, 28, 79-97.

Garnier, D., Simondon, K. B.and Benefice, E., 2005, Longitudinal estimates of puberty timing in Senegalese adolescent girls. Am J Hum Biol, 17, 718-730. 
Garruto, R. M., Little, M. A., James, G. D.and Brown, D. E., 1999, Natural experimental models: the global search for biomedical paradigms among traditional, modernizing, and modern populations. Proc Natl Acad Sci U S A, 96, 10536-10543.

Gray, S. J., Wiebusch, B.and Akol, H. A., 2004, Cross-sectional growth of pastoralist Karimojong and Turkana children. Am J Phys Anthropol, 125, 193-202.

Greaves, K. A., Puhl, J., Baranowski, T., Gruben, D.and Seale, D., 1989, Ethnic differences in anthropometric characteristics of young children and their parents. Hum Biol, 61, 459-477.

Gurney, J. M.and Jelliffe, D. B., 1973, Arm anthropometry in nutritional assessment: nomogram for rapid calculation of muscle circumference and cross-sectional muscle and fat areas. Am J Clin Nutr, 26, 912-915.

He, Q., Horlick, M., Thornton, J., Wang, J., Pierson, R. N., Jr., Heshka, S.and Gallagher, D., 2002, Sex and race differences in fat distribution among Asian, AfricanAmerican, and Caucasian prepubertal children. J Clin Endocrinol Metab, 87, 21642170.

Horlick, M. B., Rosenbaum, M., Nicolson, M., Levine, L. S., Fedun, B., Wang, J., Pierson, R. N., Jr.and Leibel, R. L., 2000, Effect of puberty on the relationship between circulating leptin and body composition. J Clin Endocrinol Metab, 85, 25092518 .

Kulin, H. E., Bwibo, N., Mutie, D.and Santner, S. J., 1982, The effect of chronic childhood malnutrition on pubertal growth and development. Am J Clin Nutr, 36, 527-536.

Lohman, T. G., Roche, A.and Martorell, R., 1988, Anthropometric standardization reference manual. Human kinetics Books, Champaign, Illinois.

Malina, R. M., Huang, Y. C.and Brown, K. H., 1995, Subcutaneous adipose tissue distribution in adolescent girls of four ethnic groups. Int J Obes Relat Metab Disord, 19, 793-797.

Malina, R. M., Koziel, S.and Bielicki, T., 1999, Variation in subcutaneous adipose tissue distribution associated with age, sex, and maturation. Am J Human Biol, 11, 189200.

Martorell, R., Mendoza, F. S., Castillo, R. O., Pawson, I. G.and Budge, C. C., 1987, Short and plump physique of Mexican-American children. Am J Phys Anthropol, 73, 475-487.

Ndiaye, G. M.and Benefice, E., 2007, Patterns of daily activity and time spent in bed of adult women and adolescent and preadolescent girls from a rural community in Senegal, West Africa. Ann Hum Biol, 34, 454-469. 
Parent, A. S., Teilmann, G., Juul, A., Skakkebaek, N. E., Toppari, J.and Bourguignon, J. P., 2003, The timing of normal puberty and the age limits of sexual precocity: variations around the world, secular trends, and changes after migration. Endocr Rev, 24, 668-693.

Pawloski, L. R., Moore, J. B., Lumbi, L.and Rodriguez, C. P., 2004, A cross-sectional examination of growth indicators from Nicaraguan adolescent girls: a comparison of anthropometric data from their Guatemalan counterparts. Ann Hum Biol, 31, 647659.

Preece, M. A.and Baines, M. J., 1978, A new family of mathematical models describing the human growth curve. Ann Hum Biol, 5, 1-24.

Riley, A. P., 1994, Determinants of adolescent fertility and its consequences for maternal health, with special reference to rural Bangladesh. Ann N Y Acad Sci, 709, 86-100.

Rolland-Cachera, M. F., Bellisle, F., Deheeger, M., Pequignot, F.and Sempe, M., 1990, Influence of body fat distribution during childhood on body fat distribution in adulthood: a two-decade follow-up study. Int J Obes, 14, 473-481.

Santos, R. V.and Coimbra Junior, C. E., 1991, Socioeconomic transition and physical growth of Tupi-Monde Amerindian children of the Aripuana Park, Brazilian Amazon. Hum Biol, 63, 795-819.

Siervogel, R. M., Demerath, E. W., Schubert, C., Remsberg, K. E., Chumlea, W. C., Sun, S., Czerwinski, S. A.and Towne, B., 2003, Puberty and body composition. Horm Res, 60, 36-45.

Simondon, K. B., Simon, I.and Simondon, F., 1997, Nutritional status and age at menarche of Senegalese adolescents. Ann Hum Biol, 24, 521-532.

Sun, S. S., Schubert, C. M., Chumlea, W. C., Roche, A. F., Kulin, H. E., Lee, P. A., Himes, J. H.and Ryan, A. S., 2002, National estimates of the timing of sexual maturation and racial differences among US children. Pediatrics, 110, 911-919.

Tanner, J., 1962, Growth at adolescence, 2nd ed. Blackwell Scientific, Oxford.

Walker, R., Gurven, M., Hill, K., Migliano, A., Chagnon, N., De Souza, R., Djurovic, G., Hames, R., Hurtado, A. M., Kaplan, H., Kramer, K., Oliver, W. J., Valeggia, C.and Yamauchi, T., 2006, Growth rates and life histories in twenty-two small-scale societies. Am J Hum Biol, 18, 295-311.

Warren, M. P.and Perlroth, N. E., 2001, The effects of intense exercise on the female reproductive system. J Endocrinol, 170, 3-11.

Williams, S.and Dickson, N., 2002, Early growth, menarche, and adiposity rebound. Lancet, 359, 580-581. 
Table I: Anthropometric characteristics of children according to age group and geographic location

\begin{tabular}{|c|c|c|c|c|c|c|c|c|}
\hline \multicolumn{9}{|c|}{ Prepubescent children (5-9.9 years old) } \\
\hline & \multicolumn{4}{|c|}{ Senegal } & \multicolumn{4}{|c|}{ Beni } \\
\hline & \multicolumn{2}{|c|}{ Boys $(n=95)$} & \multicolumn{2}{|c|}{ Girls $(n=101)$} & \multicolumn{2}{|c|}{ Boys $(n=90)$} & \multicolumn{2}{|c|}{ Girls $(n=85)$} \\
\hline & Mean & $\mathrm{SD}$ & mean & SD & Mean & $\mathrm{SD}$ & mean & $\mathrm{SD}$ \\
\hline $\begin{array}{l}\text { H-age (z- } \\
\text { scores) }\end{array}$ & 0.20 & 1.06 & 0.43 & 1.14 & -1.73 & 1.16 & -1.51 & 1.00 \\
\hline $\begin{array}{l}\text { BMI } \\
\left(\mathrm{kg} / \mathrm{m}^{2}\right)\end{array}$ & 14.73 & 1.07 & 14.47 & 1.04 & 16.63 & 1.10 & 16.22 & 1.03 \\
\hline $\begin{array}{l}\sum 4 \mathrm{skf} \\
(\mathrm{mm})\end{array}$ & 21.51 & 4.98 & 23.40 & 4.42 & 21.30 & 5.69 & 24.40 & 5.43 \\
\hline $\mathrm{AMC}(\mathrm{cm})$ & 13.18 & 1.14 & 13.00 & 1.17 & 15.88 & 1.27 & 15.45 & 1.35 \\
\hline TER & 0.83 & 0.15 & 0.84 & 0.16 & 1.08 & 0.19 & 1.10 & 0.21 \\
\hline \multicolumn{9}{|c|}{ Pubescent children (10-15 years old) } \\
\hline & \multicolumn{2}{|c|}{ Boys $(n=273)$} & \multicolumn{2}{|c|}{ Girls $(n=322)$} & \multicolumn{2}{|c|}{ Boys $(n=45)$} & \multicolumn{2}{|c|}{ Girls $(n=52)$} \\
\hline $\begin{array}{l}\text { H-age (z- } \\
\text { scores) }\end{array}$ & -1.49 & 0.95 & -1.21 & 1.13 & -1.63 & 0.84 & -1.78 & 1.17 \\
\hline $\begin{array}{l}\text { BMI } \\
\left(\mathrm{kg} / \mathrm{m}^{2}\right)\end{array}$ & 15.55 & 1.18 & 17.57 & 2.46 & 18.00 & 1.76 & 19.19 & 3.29 \\
\hline $\begin{array}{l}\sum 4 \mathrm{skf} \\
(\mathrm{mm})\end{array}$ & 17.83 & 3.15 & 33.35 & 15.14 & 25.07 & 6.43 & 32.10 & 9.60 \\
\hline $\operatorname{AMC}(\mathrm{cm})$ & 16.65 & 1.51 & 18.06 & 1.73 & 18.82 & 1.99 & 18.62 & 2.24 \\
\hline TER & 1.01 & 0.16 & 1.02 & 0.20 & 1.29 & 0.25 & 1.28 & 0.27 \\
\hline
\end{tabular}


Table II: Sex differences in body composition indices in Senegal

a) Prepubescent children

\begin{tabular}{lccccc}
\hline & Factors & $\mathrm{F}$ & $\mathrm{p}$ & Trend $^{1}$ & Conclusion \\
\hline H-age & age effect & 3.65 & 0.06 & & \\
& sex effect & 0.48 & $\mathrm{~ns}^{2}$ & $\mathrm{~ns}$ & girls=boys \\
& & & & & \\
AMC & age effect & 69.87 & 0.00 & & \\
& sex effect & 0.10 & $\mathrm{~ns}$ & $\mathrm{~ns}$ & girls=boys \\
& & & & & \\
Log BMI & age effect & 0.78 & 0.38 & & \\
& sex effect & 2.02 & $\mathrm{~ns}$ & $\mathrm{~ns}$ & girls=boys \\
& & & & & \\
$\log \sum$ 4 skf & age effect & 16.73 & 0.00 & & \\
& sex effect & 6.84 & 0.01 & 0.01 & girls $>$ boys \\
& & & & & \\
Log TER & age effect & 20.77 & 0.00 & & \\
& sex effect & 0.01 & $\mathrm{~ns}$ & $\mathrm{~ns}$ & girls=boys \\
\hline
\end{tabular}

b) Pubescent children

\begin{tabular}{lccccc}
\hline & Factors & $\mathrm{F}$ & $\mathrm{p}$ & Trend $^{1}$ & Conclusion \\
\hline H-age & age effect & 28.41 & 0.00 & & \\
& sex effect & 27.41 & 0.00 & 0.000 & girls $>$ boys \\
& & & & & \\
AMC & age effect & 132.87 & 0.00 & & \\
& sex effect & 5.95 & 0.01 & 0.00 & girls $>$ boys \\
& & & & & \\
Log BMI & age effect & 71.06 & 0.00 & & \\
& sex effect & 23.72 & 0.00 & 0.000 & girls $>$ boys \\
& & & & & \\
$\log \sum$ 4 skf & age effect & 35.03 & 0.00 & & \\
& sex effect & 170.19 & 0.00 & 0.000 & girls $>$ boys \\
& & & & & \\
Log TER & age effect & 3.94 & 0.04 & & \\
& sex effect & 1.44 & ns & ns & girls $=$ boys \\
\hline
\end{tabular}

${ }^{1} \mathrm{p}$ for linear trend in sex comparisons

$2:$ ns $=$ not significant 
Table III: Sex differences in body composition indices in Beni (Bolivia)

a) Prepubescent children

\begin{tabular}{lccccc}
\hline & Factors & $\mathrm{F}$ & $\mathrm{p}$ & Trend & Conclusion \\
\hline H-age & age effect & 0.73 & $\mathrm{~ns}$ & & \\
& sex effect & 1.82 & $\mathrm{~ns}$ & $\mathrm{~ns}$ & girls=boys \\
& & & & & \\
AMC & age effect & 30.50 & 0.00 & & \\
& sex effect & 4.27 & 0.04 & 0.01 & girls $<$ boys \\
& & & & & \\
Log BMI & age effect & 3.44 & 0.07 & & \\
& sex effect & 11.83 & 0.00 & 0.00 & girls $<$ boys \\
& & & & & \\
Log 4 skf & age effect & 1.77 & ns & & \\
& sex effect & 4.44 & 0.04 & 0.01 & girls $>$ boys \\
& & & & & \\
Log TER & age effect & 5.15 & 0.02 & & \\
& sex effect & 0.79 & 0.38 & ns & boys $=$ girls \\
\hline
\end{tabular}

b) Pubescent children

\begin{tabular}{lcrccc}
\hline & Factors & \multicolumn{1}{c}{$\mathrm{F}$} & $\mathrm{p}$ & Trend & Conclusion \\
\hline Stature & age effect & 0.06 & $\mathrm{~ns}$ & & \\
& sex effect & 1.72 & $\mathrm{~ns}$ & $\mathrm{~ns}$ & girls=boys \\
& & & & & \\
AMC & age effect & 27.85 & 0.00 & & \\
& sex effect & 0.43 & ns & ns & girls=boys \\
& & & & & \\
Log BMI & age effect & 22.94 & 0.00 & & \\
& sex effect & 8.90 & 0.00 & 0.007 & girls $>$ boys \\
& & & & & \\
$\log \sum 4$ skf & age effect & 5.44 & 0.02 & & \\
& sex effect & 23.94 & 0.00 & 0.000 & girls $>$ boys \\
& & & & & \\
$\log$ TER & age effect & 7.24 & 0.01 & & \\
& sex effect & 0.00 & ns & ns & girls=boys \\
\hline
\end{tabular}


Table IV: Differences in body composition indices according to geographic location1 (boys)

a) Prepubescent boys

\begin{tabular}{|c|c|c|c|c|c|}
\hline & Factors & $\mathrm{F}$ & $\mathrm{p}$ & Trend & Conclusion \\
\hline \multirow[t]{2}{*}{ H-age } & age effect & 1.86 & ns & & \\
\hline & population effect & 113.78 & 0.00 & 0.00 & Beni $<$ Senegal \\
\hline \multirow[t]{2}{*}{$\mathrm{AMC}$} & age effect & 38.01 & 0.00 & & \\
\hline & population effect & 124.67 & 0.00 & 0.00 & Beni $>$ Senegal \\
\hline \multirow[t]{2}{*}{ Log BMI } & age effect & 0.79 & ns & & \\
\hline & population effect & 111.91 & 0.00 & 0.00 & Beni $>$ Senegal \\
\hline \multirow[t]{2}{*}{$\log \sum 4 \mathrm{skf}$} & age effect & 9.93 & 0.00 & & \\
\hline & population effect & 1.19 & ns & ns & Beni=Senegal \\
\hline \multirow[t]{2}{*}{ Log TER } & age effect & 6.74 & 0.01 & & \\
\hline & population effect & 63.65 & 0.00 & 0.00 & Beni $>$ Senegal \\
\hline
\end{tabular}

b) Pubescent boys

\begin{tabular}{lccccc}
\hline & Factors & $\mathrm{F}$ & $\mathrm{p}$ & Trend & Conclusion \\
\hline H-age & age effect & 0.98 & $\mathrm{~ns}$ & & \\
& population effect & 0.50 & $\mathrm{~ns}$ & $\mathrm{~ns}$ & Beni=Senegal \\
AMC & $\begin{array}{c}\text { age effect } \\
\text { population effect }\end{array}$ & 62.58 & 0.00 & & \\
& & & & & \\
Log BMI & age effect & 26.56 & 0.00 & & \\
& population effect & 139.13 & 0.00 & 0.00 & Beni>Senegal \\
Log 4 skf & $\begin{array}{c}\text { age effect } \\
\text { population effect }\end{array}$ & 0.83 & ns & & \\
& & 0.64 & 0.00 & 0.00 & Beni $>$ Senegal \\
Log TER & age effect & 4.11 & 0.04 & & \\
& population effect & 76.15 & 0.00 & 0.00 & Beni>Senegal \\
\hline
\end{tabular}

${ }^{1}$ : Two populations according to geographic location: rural Senegal and lowland Bolivia (Beni) 
Table V: Differences in body composition indices according to geographic location1 (girls)

a) Prepubescent girls

\begin{tabular}{lccccc}
\hline & Factors & $\mathrm{F}$ & $\mathrm{p}$ & Trend & Conclusion \\
\hline H-age & age effect & 0.33 & $\mathrm{~ns}$ & & \\
& population effect & 92.74 & 0.00 & 0.00 & Beni $<$ Senegal \\
& & & & & \\
AMC & age effect & 52.23 & 0.00 & & \\
& population effect & 72.57 & 0.00 & 0.00 & Beni $>$ Senegal \\
& & & & & \\
Log BMI & age effect & 3.71 & 0.06 & & \\
& population effect & 69.87 & 0.00 & 0.00 & Beni $>$ Senegal \\
Log $\sum$ 4 skf & age effect & 2.81 & $\mathrm{~ns}$ & & \\
& population effect & 2.91 & $\mathrm{~ns}$ & 0.03 & Beni $>$ Senegal \\
& & & & & \\
Log TER & age effect & 15.20 & 0.00 & & \\
& population effect & 38.68 & 0.00 & 0.00 & Beni $>$ Senegal \\
\hline
\end{tabular}

b) Pubescent girls

\begin{tabular}{lccccc}
\hline & Factors & $\mathrm{F}$ & $\mathrm{p}$ & trend & conclusion \\
\hline Stature & age effect & 5.38 & 0.02 & & \\
& population effect & 18.46 & 0.00 & 0.00 & Beni $<$ Senegal \\
AMC & age effect & 49.74 & 0.00 & & \\
& population effect & 41.76 & 0.00 & 0.00 & Beni $>$ Senegal \\
& & & & & \\
Log BMI & age effect & 41.72 & 0.00 & & \\
& population effect & 60.06 & 0.00 & 0.00 & Beni $>$ Senegal \\
& & & & & \\
Log $\sum$ skf & age effect & 19.73 & 0.00 & & \\
& population effect & 9.47 & 0.00 & 0.00 & Beni $>$ Senegal \\
& & & & & \\
Log TER & age effect & 7.44 & 0.00 & & \\
& population effect & 61.17 & 0.00 & 0.00 & Beni $>$ Senegal \\
\hline
\end{tabular}

${ }^{1}$ : Two populations according to geographic location: rural Senegal and lowland Bolivia (Beni) 